\title{
Curcumin induces apoptosis and inhibits angiogenesis in murine malignant mesothelioma
}

\author{
CHENGKE ZHANG $^{1 *}$, YINGTAO HAO $^{1 *}$, LICUN WU $^{1,2}$, XIAOPENG DONG $^{1}$, NING JIANG ${ }^{1}$, BO CONG $^{1}$, \\ JIANG LIU ${ }^{3}$, WEN ZHANG ${ }^{3}$, DONGQI TANG $^{3}$, MARC DE PERROT $^{2}$ and XIAOGANG ZHAO ${ }^{1}$ \\ ${ }^{1}$ Department of Thoracic Surgery, The Second Hospital of Shandong University, Jinan, Shandong 250033, P.R. China; \\ ${ }^{2}$ Latner Thoracic Surgery Research Laboratories and Division of Thoracic Surgery, Toronto General Hospital, \\ University Health Network, University of Toronto, Toronto, ON M5G 2C4, Canada; ${ }^{3}$ Gene and Immunotherapy Center, \\ The Second Hospital of Shandong University, Jinan, Shandong 250033, P.R. China
}

Received June 26, 2018; Accepted August 21, 2018

DOI: $10.3892 /$ ijo.2018.4569

\begin{abstract}
Malignant pleural mesothelioma (MPM) is a rare form of cancer that is associated with asbestos exposure. Unfortunately, current therapies have limited efficacy. Previous studies have indicated that curcumin exerts antiproliferative and antitumor effects, and has low toxicity. The present study aimed to evaluate the anticancer effects of curcumin on the RN5 MPM cell line. The inhibitory effects of curcumin on cell viability were determined using the sulforhodamine B assay. In addition, cell cycle progression was analyzed by propidium iodide (PI) staining and flow cytometry, and curcumin-induced apoptosis was measured by Annexin V/PI double staining. The translocation of apoptosis-inducing factor (AIF) was assessed by western blotting and immunofluorescence, and the expression levels of the phosphoinositide 3-kinase (PI3K)-AKT serine/ threonine kinase (Akt)-mammalian target of rapamycin (mTOR) signaling pathway proteins and mitochondria-associated proteins were evaluated by western blotting. In vivo antitumor effects were evaluated in a subcutaneous murine model. Briefly, tumors were harvested from the mice, and immunohistochemistry was conducted to evaluate cell proliferation, apoptosis and angiogenesis. The results indicated that curcumin inhibited RN5 cell viability and induced apoptotic cell death.
\end{abstract}

Correspondence to: Dr Marc de Perrot, Latner Thoracic Surgery Research Laboratories and Division of Thoracic Surgery, Toronto General Hospital, University Health Network, University of Toronto, 9N-961, 200 Elizabeth Street, Toronto, ON M5G 2C4, Canada E-mail: marc.deperrot@uhn.ca

Dr Xiaogang Zhao, Department of Thoracic Surgery, The Second Hospital of Shandong University, 247 Beiyuan Road, Jinan, Shandong 250033, P.R. China

E-mail: zhaoxiaogang@sdu.edu.cn

${ }^{*}$ Contributed equally

Key words: curcumin, malignant pleural mesothelioma, apoptosis, apoptosis-inducing factor, phosphoinositide 3-kinase-AKT serine/ threonine kinase-mammalian target of rapamycin
In addition the findings suggested that curcumin-induced cell apoptosis occurred via the mitochondrial pathway, and caspase-independent and AIF-dependent pathways. Further analysis revealed that curcumin may act as a PI3K-Akt-mTOR signaling pathway inhibitor by downregulating PI3K, p-Akt, p-mTOR and p-p70 ribosomal protein S6 kinase. Furthermore, curcumin inhibited tumor angiogenesis in vivo. In conclusion, curcumin may be potent enough to be developed as a novel therapeutic agent for the treatment of MPM.

\section{Introduction}

Malignant pleural mesothelioma (MPM) is a type of rare, aggressive and chemoradiation-resistant cancer, which is most commonly caused by asbestos exposure (1-3). Malignant mesothelioma arises from the mesothelial cells of serous membranes, including the pleura, peritoneum and pericardium. The 5-year survival rate of MPM is $\sim 10 \%$ (4).

The majority of chemotherapeutic agents exhibit restricted efficacy in MPM treatment. Cisplatin plus pemetrexed is the most commonly used first-line regimen for MPM chemotherapy, which is approved by the US Food and Drug Administration. In patients with MPM, chemotherapy failure is often attributed to resistance to cytotoxic drug-induced apoptosis; therefore, the discovery of novel drugs that have proapoptotic effects on MPM cells or that target sensitive signaling pathways may result in more effective strategies to improve the outcome of MPM $(5,6)$.

Curcumin is an active ingredient of turmeric and curry powder, which has been reported to possess anti-inflammatory, antiviral, antibacterial, antifungal and anti-oxidant properties. In addition, numerous studies have revealed that curcumin exerts marked antitumor effects in various types of cancer $(7,8)$. Furthermore, curcumin, in combination with chemotherapy, has been investigated in clinical trials for the treatment of patients with prostate cancer or breast cancer. Although curcumin induces MPM cell death through pathways associated with pyroptosis (9), autophagy (10) and apoptosis $(11,12)$, how curcumin induces apoptosis in MPM remains to be elucidated. In addition, whether curcumin induces angiogenesis in vivo has yet to be studied. 
The present study aimed to identify the antitumor effects of curcumin, as well as its possible targets and affected signaling pathways in RN5 murine mesothelioma cells. The results demonstrated that curcumin significantly inhibited RN5 cell viability. The antitumor activity of curcumin was also confirmed in RN5 mouse models, thus indicating that it was highly effective in inhibiting tumor growth. The molecular basis of these antitumor effects was also investigated.

\section{Materials and methods}

Reagents. Curcumin (cat. no. S1848; Selleck Chemicals, Houston, TX, USA) was dissolved in dimethyl sulfoxide (DMSO) and stored at $4^{\circ} \mathrm{C}$ as a stock solution. Cisplatin (cat. no. S1166; Selleck Chemicals) was dissolved in normal saline and stored at room temperature. RPMI-1640 medium, fetal bovine serum (FBS), penicillin, streptomycin and all other cell culture reagents were obtained from Thermo Fisher Scientific, Inc. (Waltham, MA, USA). Primary antibodies against cleaved-poly (ADP-ribose) polymerase (PARP) (cat. no. 9548), caspase-3 (cat. no. 9665), cleaved caspase-3 (cat. no. 9664), caspase-8 (cat. no. 4927), cleaved caspase-8 (cat. no. 8592), caspase-9 (cat. no. 9504), PI3K (cat. no. 4257), AKT serine/threonine kinase (Akt) (cat. no. 4691), phosphorylated (p)-Akt (Ser473) (cat. no. 9271), mammalian target of rapamycin (mTOR) (cat. no. 2972), p-mTOR (Ser2448) (cat. no. 5536), p70 ribosomal protein S6 kinase (p70S6K) (cat.no.2708),p-p70S6K(Thr389) (cat.no.9234) and Histone H3 (cat.no. 4499) were purchased from Cell Signaling Technology, Inc. (Danvers, MA, USA). Primary antibodies against $\beta$-actin (cat. no. YT0099) and GAPDH (cat. no. YT5052) were purchased from ImmunoWay Biotechnology Company (Plano, TX, USA). Primary antibodies against apoptosis-inducing factor (AIF) (cat. no. ab1998), B-cell lymphoma (Bcl)-extra large (xL) (cat. no. ab32370), Bcl-2-associated X protein (Bax) (cat. no. ab32503), cluster of differentiation (CD)31 (cat. no. ab28364) and Ki67 (cat. no. ab15580) were purchased from Abcam (Cambridge, MA, USA). Horseradish peroxidase (HRP)-conjugated secondary antibodies [Anti-rabbit immunoglobulin G (IgG), HRP-linked Antibody \#7074 or Anti-mouse IgG, HRP-linked Antibody \#7076] were purchased from Cell Signaling Technology, Inc. Polyvinylidene difluoride (PVDF) membranes and western blot luminescence reagents were purchased from EMD Millipore (Billerica, MA, USA). Cell cycle assay kit and cell apoptosis kit were purchased from Nanjing KeyGen Biotech Co., Ltd. (Nanjing, China). Alexa Fluor-555-conjugated goat anti-rabbit IgG antibody (cat. no. A27039), and the nuclear and cytoplasmic extraction kit were purchased from Thermo Fisher Scientific, Inc.

Cell culture. The RN5 murine malignant mesothelioma cell line (13), which was kindly gifted by Dr Marc de Perrot's Laboratory (Toronto General Hospital, Toronto, ON, Canada), was maintained in RPMI-1640 medium supplemented with $10 \% \mathrm{FBS}$ and $100 \mu \mathrm{g} / \mathrm{ml}$ penicillin-streptomycin. The cells were maintained at $37^{\circ} \mathrm{C}$ in the presence of $5 \% \mathrm{CO}_{2}$.

Cytotoxicity assay. The inhibitory effects of curcumin were determined using the sulforhodamine B (SRB) assay. Briefly, RN5 cells were seeded at $4 \times 10^{3}$ cells/well in 96-well flat-bottom plates for $24 \mathrm{~h}$ at $37^{\circ} \mathrm{C}$. The cells were then treated with curcumin or cisplatin at various concentrations for $72 \mathrm{~h}$ at $37^{\circ} \mathrm{C}$ in the presence of $5 \% \mathrm{CO}_{2}$. The optical density (OD) was measured at $510 \mathrm{~nm}$ using a microplate reader. The percentage of cells that were killed was calculated using the following formula: $100 \%-\mathrm{OD}_{\text {sample }} / \mathrm{OD}_{\text {control }}$. Half maximal effective concentration $\left(\mathrm{EC}_{50}\right)$ values were calculated using Sigmaplot 12.0 software (Systat Software Inc., San Jose, CA, USA).

Protein extraction and western blot analysis. Cells were seeded in a $10-\mathrm{cm}$ dish $\left(10^{6}\right.$ cells/dish) and were incubated at $37^{\circ} \mathrm{C}$ for $24 \mathrm{~h}$. Cells were then treated with vehicle control (DMSO 0.1\%), various doses of curcumin $(15,20$ and $25 \mu \mathrm{M})$ or cisplatin $(30 \mu \mathrm{M})$ for $24 \mathrm{~h}$, after which, cells were lysed with extraction buffer (cat. no. FNN0011; Thermo Fisher Scientific, Inc.) supplemented with protease inhibitor (cat. no. P8340; Sigma-Aldrich; Merck KGaA, Darmstadt, Germany), phosphatase inhibitor (cat. no. 4906845001; Roche Diagnostics, Basel, Switzerland) and $1 \mathrm{mM}$ phenylmethylsulfonyl fluoride. Protein concentration was determined using the Pierce $^{\mathrm{TM}}$ bicinchoninic acid protein assay kit (Thermo Fisher Scientific, Inc.). Equal volumes of protein (15-40 $\mu \mathrm{g}$ ) were separated by $10 \%$ SDS-PAGE and were electrophoretically transferred onto PVDF membranes. The membranes were blocked with $5 \%$ non-fat milk in Tris-buffered saline (TBS) with $0.1 \%$ Tween-20 and were agitated for $1 \mathrm{~h}$ at room temperature. Subsequently, the membranes were incubated overnight at $4^{\circ} \mathrm{C}$ with specific primary antibodies $(1: 1,000$, in $5 \%$ non-fat dry milk or bovine serum albumin (cat. no. B2064; Sigma-Aldrich; Merck KGaA) in TBS with 0.1\% Tween-20). The membranes were washed three times with TBS containing $0.1 \%$ Tween-20 solution and were then incubated with the secondary antibodies (1:5,000, in 5\% non-fat milk in TBS with $0.1 \%$ Tween-20). After secondary antibody incubation, the membranes were washed three times with TBS with $0.1 \%$ Tween-20 and the proteins were detected using the Luminata Forte Western HRP substrate (EMD Millipore), according to the manufacturer's protocol. Band intensity was analyzed using ImageJ 1.51 software (National Institutes of Health, Bethesda, MD, USA), according to previous studies $(14,15)$.

Cell cycle analysis. RN5 cells were seeded in a 6-well plate at a cell density of $2 \times 10^{5}$ cells/well. The cells were treated with various concentrations of curcumin for $24 \mathrm{~h}$, whereas cisplatin $(30 \mu \mathrm{M})$ was used to treat cells as a positive control. After treatment, cells were harvested, washed twice with PBS and fixed in $70 \%$ ethanol at $-20^{\circ} \mathrm{C}$ overnight. After washing, the cells were suspended in PBS containing $50 \mu \mathrm{g} / \mathrm{ml}$ propidium iodide (PI) and were incubated at $4^{\circ} \mathrm{C}$ for at least $4 \mathrm{~h}$. Cell cycle analysis was performed using flow cytometry. Fluorescence was measured using the BD FACSCanto II flow cytometer (BD Biosciences, Franklin Lakes, NJ, USA) and cell cycle progression was estimated using Modfit LT 4.1 Software (Verity Software House, Inc., Topsham, ME, USA).

Cell apoptosis assay. RN5 cells were seeded in a 6-well plate at a cell density of $2 \times 10^{5}$ cells/well. The cells were treated with various concentrations of curcumin for $24 \mathrm{~h}$, whereas 
cisplatin $(30 \mu \mathrm{M})$ was used to treat cells as a positive control. The cells were then collected and washed twice with cold PBS. Annexin V-PI (AV-PI) double staining was performed according to the manufacturer's protocol. Apoptosis was analyzed using the BD FACSCanto II flow cytometer (BD Biosciences) and FlowJo version 10.0.7 (FlowJo LLC, Ashland, OR, USA).

In vivo tumor models. To evaluate the in vivo effects of curcumin, the effects of curcumin on tumor growth were investigated in tumor-bearing mice. The animal study was approved by the Committee on the Ethics on Animal Experimentation of The Second Hospital of Shandong University [no. KYLL-2017(LW) 011, approved February 3, 2017; Jinan, China]. A total of 20 male C57BL/6J mice (weight, 20-25 g; age, 6 weeks) were purchased from Beijing Vital River Laboratory Animal Technology Co., Ltd. (Beijing, China) and were housed under pathogen-free conditions. The mice were maintained in a temperature-controlled room $\left(22-24^{\circ} \mathrm{C}\right)$ with a relative humidity between 55 and $65 \%$ under a 12-h light/dark cycle. Food and water were freely available. RN5 cells $\left(5 \times 10^{6}\right.$ cells in $100 \mu$ l PBS) were injected subcutaneously into the dorsal flank of each mouse. When the tumors reached volumes of $60 \mathrm{~mm}^{3}$, the animals were randomly assigned into four groups. The mice were treated five times every 5 days with intraperitoneal administration of i) $200 \mu \mathrm{l}$ solvent (PBS/cremophor/DMSO/ethanol, 15:3:1:1); ii) curcumin at a low dose $(200 \mathrm{mg} / \mathrm{kg})$; or iii) curcumin at a high dose $(500 \mathrm{mg} / \mathrm{kg})$. As a positive control, another group of mice was treated with cisplatin at a dose of $5 \mathrm{mg} / \mathrm{kg}$. Cisplatin was dissolved in normal saline at a final concentration of $1 \mathrm{mg} / \mathrm{ml}$. Body weight was measured every day in order to monitor the toxicity of the treatments. Tumor volumes were determined using the following formula: $a \times b^{2} / 2$, where ' $a$ ' is the longest diameter and ' $b$ ' is the shortest diameter. The mice were euthanized by $\mathrm{CO}_{2}$ inhalation when the tumor in the solvent-treated group grew to $15 \mathrm{~mm}$ in diameter. The tumor samples were then collected and were fixed in $10 \%$ formalin neutral buffer solution for at least $24 \mathrm{~h}$ at room temperature. Sections were then paraffin-embedded.

Preparation of nuclear and cytoplasmic extracts for western blot analysis. RN5 cells were seeded into a 10-cm Petri dish $\left(10^{6} \mathrm{cells} / \mathrm{dish}\right)$ and were incubated at $37^{\circ} \mathrm{C}$ for $24 \mathrm{~h}$. Cells were then treated with vehicle control (DMSO 0.1\%), three doses of curcumin $(15,20$ and $25 \mu \mathrm{M})$ for $24 \mathrm{~h}$. After treatment, cells were trypsinized, and nuclear and cytoplasmic fractions were isolated according to the manufacturer's protocol, using NE-PER ${ }^{\circledR}$ Nuclear and Cytoplasmic Extraction reagents (Thermo Fisher Scientific, Inc.). After isolation of nuclear and cytoplasmic fractions, western blotting was performed using antibodies specific for the nuclear fraction of AIF and Histone $\mathrm{H} 3$.

Immunohistochemistry and histological analysis. Paraffinembedded sections $(5 \mu \mathrm{m})$ of tumor tissues were mounted on gelatin-coated histological slides, deparaffinized with xylene, and rehydrated in a descending series of alcohol (100-70\%) and distilled water at room temperature for $5 \mathrm{~min}$. Antigen retrieval was performed by microwaving the slides in $10 \mathrm{mM}$ citrate buffer (pH 6.0) for $20 \mathrm{~min}$. Endogenous peroxidase activity was quenched by incubation with $3 \% \mathrm{H}_{2} \mathrm{O}_{2}$ for 20 min, after which, the sections were blocked with $1.5 \%$ goat serum (Beyotime Institute of Biotechnology, Shanghai, China) for $60 \mathrm{~min}$ at room temperature to prevent non-specific binding. The sections were then incubated overnight at $4^{\circ} \mathrm{C}$ with primary antibodies against CD31 and Ki67 (1:100). The slides were washed three times with PBS containing 0.1\% Tween-20 (5 min/wash) and were incubated with a secondary antibody $(1: 10,000)$ [Goat anti-Rabbit IgG H\&L (HRP), cat. no. ab205718; Abcam] for $1 \mathrm{~h}$ at room temperature. Immunohistochemical staining for CD31 and Ki67 was further performed using the avidin-biotin peroxidase complex method, with diaminobenzidine (DAB) as a chromogenic substrate. Immunostained sections were counterstained with hematoxylin staining solution (Beyotime Institute of Biotechnology) for $40 \mathrm{sec}$ at room temperature, and were then examined by light microscopy.

To semi-quantitatively analyze tumor cell proliferation and apoptosis in tumor sections, the $\mathrm{H}$-score was used to evaluate the expression of Ki67-positive cells, as previously reported $(16,17)$. The $\mathrm{H}$-score was calculated using the following formula: ( $0 \mathrm{x}$ percentage of negative staining) $+(1 \mathrm{x}$ percentage of weak staining $)+(2 \mathrm{x}$ percentage of moderate staining $)+(3 \mathrm{x}$ percentage of strong staining $)$. Staining intensity was classified as follows: Negative staining (no staining), weak staining (light yellow), moderate staining (yellowish brown) and strong staining (tan). The values ranged between 0 and 300. CD31-positive area was used to analyze angiogenesis.

TUNEL staining. For TUNEL staining of tumor tissue samples, proteolytic digestion was conducted by incubating the sections for $10 \mathrm{~min}$ at room temperature with proteinase $\mathrm{K}(10 \mu \mathrm{g} / \mathrm{ml})$, after which, they were fixed in $4 \%$ paraformaldehyde solution for $5 \mathrm{~min}$ at room temperature. After rinsing with PBS, the samples were permeabilized in equilibration buffer for $5 \mathrm{~min}$. Samples were then incubated with recombinant terminal deoxynucleotidyl transferase reaction mix for $60 \mathrm{~min}$ at $37^{\circ} \mathrm{C}$, washed in saline sodium citrate solution for $15 \mathrm{~min}$, and then quenched with $0.3 \% \mathrm{H}_{2} \mathrm{O}_{2}$ in PBS for $5 \mathrm{~min}$. After washing with PBS, the samples were incubated with HRP-labeled streptavidin for $30 \mathrm{~min}$ at room temperature and DAB was applied as a chromogenic substrate. The sections were then dehydrated through a graded series of alcohol, immersed in xylene and mounted with coverslips. The sections were examined under an Olympus BX43 light microscope (Olympus Corporation, Tokyo, Japan). The H-score was used to evaluate the expression of TUNEL-positive cells, as aforementioned.

Immunofluorescence. RN5 cells were seeded onto glass coverslips at $2 \times 10^{5}$ cells in a 6 -well plate overnight at $37^{\circ} \mathrm{C}$ in the presence of $5 \% \mathrm{CO}_{2}$. Subsequently, cells were treated with 15,20 or $25 \mu \mathrm{M}$ curcumin at $37^{\circ} \mathrm{C}$ for $24 \mathrm{~h}$, after which, cells were rinsed with cold PBS and fixed with $4 \%$ paraformaldehyde for $30 \mathrm{~min}$ at room temperature. Fixed cells were washed with PBS and were permeabilized with $1 \%$ Triton X-100 in PBS for $10 \mathrm{~min}$. Cells were then blocked with goat serum for $30 \mathrm{~min}$ at room temperature and were incubated with AIF primary antibodies (1:500) overnight at $4^{\circ} \mathrm{C}$. After washing with PBS three times $(5 \mathrm{~min} /$ wash), fixed cells were incubated with Alexa Fluor-555-conjugated goat anti-rabbit IgG antibody at 

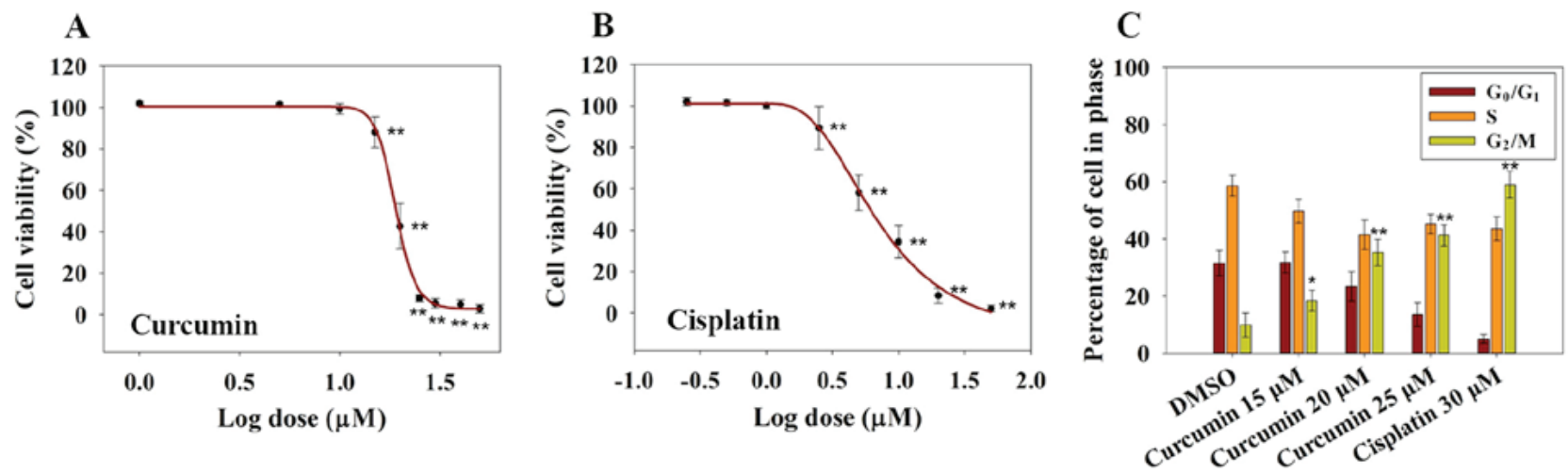

Figure 1. Cytotoxic and cell cycle-altering effects of curcumin on RN5 cells. (A) Effects of curcumin on the viability of RN5 cells. RN5 cells were treated with curcumin at concentrations of $1,5,10,15,20,25,30,40$ or $50 \mu \mathrm{M}$ for $72 \mathrm{~h}$. Data are presented as the means \pm standard deviation from three independent experiments. "* $\mathrm{P}<0.01$ vs. the $1 \mu \mathrm{M}$ (log value, 0 ) curcumin group. (B) Effects of cisplatin on the viability of RN5 cells. RN5 cells were treated with cisplatin at concentrations of $0.25,0.5,1,2.5,5,10,20$ or $50 \mu \mathrm{M}$ for $72 \mathrm{~h}$. Data are presented as the means \pm standard deviation from three independent experiments. ${ }^{* *} \mathrm{P}<0.01$ vs. the $0.25 \mu \mathrm{M}$ (log value, -0.602) cisplatin group. (C) Cell cycle analysis of RN5 cells treated with curcumin (15, 20 and $\left.25 \mu \mathrm{M}\right)$ and cisplatin $(30 \mu \mathrm{M})$ for $24 \mathrm{~h}$. Data are presented as the means \pm standard deviation from three independent experiments. ${ }^{*} \mathrm{P}<0.05$ and ${ }^{* * *} \mathrm{P}<0.01$ vs. the DMSO group. DMSO, dimethyl sulfoxide.

room temperature for $1 \mathrm{~h}$. After washing three times with $0.1 \%$ Tween-20 in PBS, the coverslips were mounted with mounting medium containing DAPI (Abcam). Cells were examined under an Olympus BX43 fluorescence microscope (Olympus Corporation).

Statistical analysis. The data are presented as the means \pm standard deviation. All of the statistical analyses were performed using Sigmaplot 12.0. Statistical comparisons between the control and treatment groups, as well as differences within the experimental groups at different doses, were conducted using one-way analysis of variance followed by least-significant difference or Tukey's tests. $\mathrm{P}<0.05$ was considered to indicate a statistically significant difference.

\section{Results}

Curcumin inhibits cell viability and induces $G_{2} / M$ phase arrest. To investigate the inhibitory effects of curcumin on RN5 cell viability, RN5 cells were treated with increasing concentrations of curcumin. Cisplatin was used as a positive control. Cell viability was determined following treatment with increasing concentrations of curcumin for $72 \mathrm{~h}$ (Fig. 1A). The results demonstrated that curcumin induced a significant inhibition in RN5 cell viability in a dose-dependent manner, as measured by the SRB assay at $72 \mathrm{~h}$, relative to control cells (Fig. 1A). The $\mathrm{EC}_{50}$ value of curcumin at $72 \mathrm{~h}$ was $19.1 \pm 1.3 \mu \mathrm{M}$, whereas the $\mathrm{EC}_{50}$ value of cisplatin was $7.09 \pm 1.14 \mu \mathrm{M}$ (Fig. 1B). These findings indicated that curcumin may inhibit MPM cell viability in a dose-dependent manner. In addition, $5 \mu \mathrm{M}$ cisplatin killed $\sim 50 \%$ of RN5 cells after $72 \mathrm{~h}$ of treatment, whereas $20 \mu \mathrm{M}$ curcumin provoked similar effects, thus suggesting that cisplatin is more cytotoxic to RN5 cells than curcumin.

Previous studies have reported that curcumin induces $\mathrm{G}_{1} / \mathrm{S}$ or $\mathrm{G}_{2} / \mathrm{M}$ cell cycle arrest in numerous types of human cancer cells $(18,19)$. In order to investigate whether curcumin induced a cell cycle arrest in RN5 cells, cell cycle distribution was examined following treatment with curcumin for
$24 \mathrm{~h}$. As shown in Fig. 1C, $<10 \%$ of RN5 cells were in $\mathrm{G}_{2} / \mathrm{M}$ phase in the DMSO groups. Conversely, 18, 35 and $41 \%$ of cells were in $\mathrm{G}_{2} / \mathrm{M}$ phase in the 15,20 and $25 \mu \mathrm{M}$ curcumin groups after $24 \mathrm{~h}$, respectively. These findings indicated that $25 \mu \mathrm{M}$ curcumin resulted in an obvious $\mathrm{G}_{2} / \mathrm{M}$ cell phase arrest. Curcumin may inhibit cell viability in a dose-dependent manner and may induce $\mathrm{G}_{2} / \mathrm{M}$ cell phase arrest.

AIF mediates curcumin-induced apoptotic cell death. It is well accepted that cell cycle arrest at $\mathrm{G}_{2} / \mathrm{M}$ phase leads to apoptotic cell death. The present study assessed curcumin-induced RN5 cell apoptosis using flow cytometry. AV-PI staining indicated that treatment with $15 \mu \mathrm{M}$ curcumin markedly increased early and late apoptosis. Treatment of RN5 cells with 15, 20 and $25 \mu \mathrm{M}$ curcumin for $24 \mathrm{~h}$ induced an increase in the percentage of AV- and PI-positive cells (Fig. 2A).

Apoptosis is induced via two main routes, involving either the caspase-dependent or caspase-independent pathway. It has previously been demonstrated that mitochondria or activation of the death receptor pathway converge to induce the activation of caspases, which are the final executioners of cell death (20). However, treatment of RN5 cells with increasing doses of curcumin did not affect the expression levels of activated caspase-3, -8 or -9 after 24 h (Fig. 2B).

Increased levels of the proapoptotic protein Bax and decreased levels of the anti-apoptotic protein Bcl-xL were observed in response to curcumin (Fig. 2C). Furthermore, cleaved-PARP expression was also increased (Fig. 2C). These results demonstrated that curcumin-induced apoptosis may be mediated by the mitochondrial pathway.

Notably, caspase-independent forms of apoptosis are mediated by AIF. To explore whether AIF nuclear translocation was involved in curcumin-induced apoptosis, subcellular AIF protein expression was measured by western blotting and AIF nuclear translocation was detected by immunofluorescence (Fig. 3A and B). Nuclear AIF expression was significantly increased after $24 \mathrm{~h}$ curcumin treatment in a dose-dependent manner. In addition, AIF-positive immunofluorescence was increased in the nucleus in a dose-dependent manner. These 
A

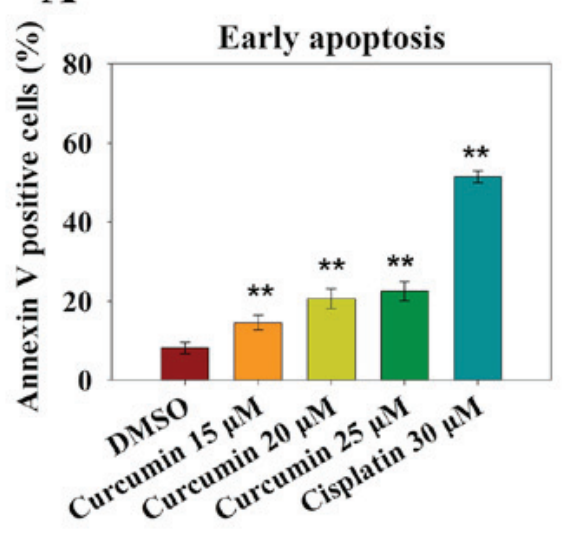

B

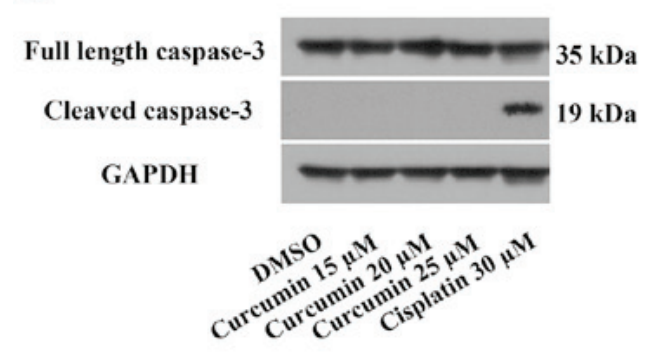

C
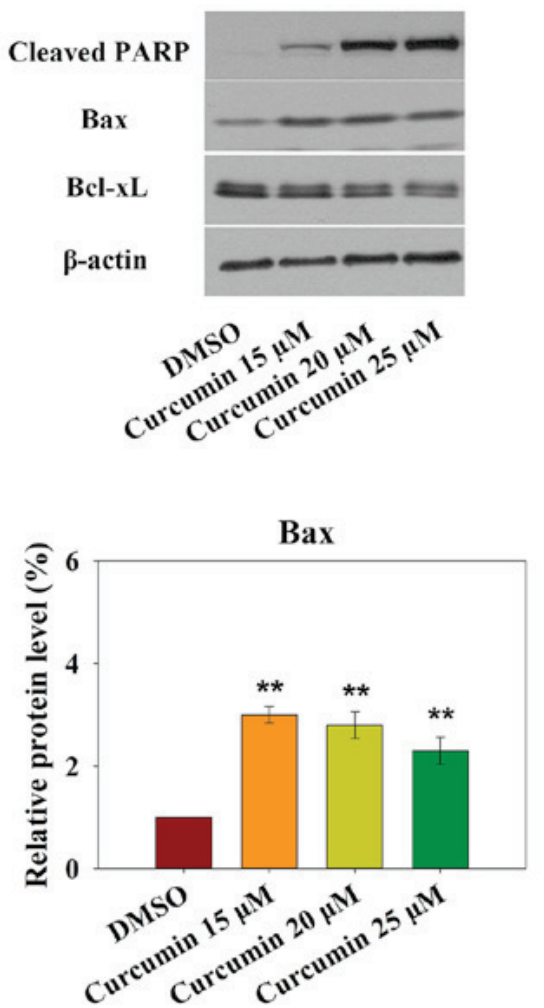

Late apoptosis
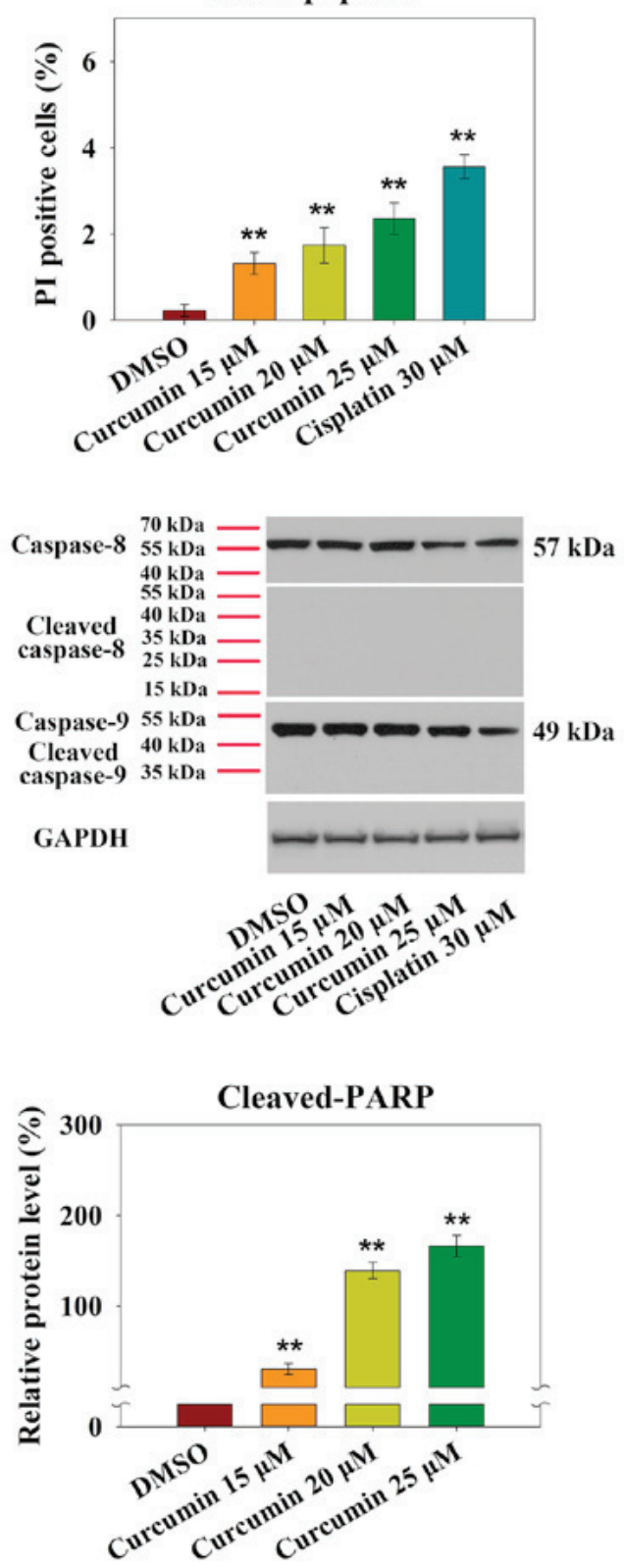

Bcl-xL

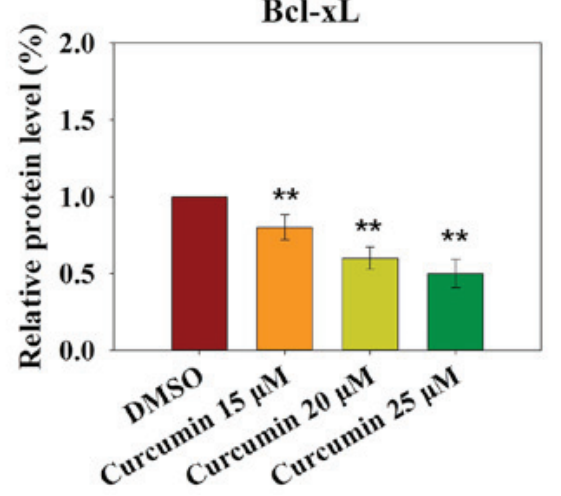

Figure 2. Treatment of murine RN5 cells with curcumin for $24 \mathrm{~h}$ induces apoptosis. (A) Percentage of RN5 cells undergoing early and late apoptosis following treatment with curcumin $(15,20$ and $25 \mu \mathrm{M})$ or cisplatin $(30 \mu \mathrm{M})$ for $24 \mathrm{~h}$. RN5 cells were stained with Annexin V and PI, and were analyzed by flow cytometry. (B) Curcumin induced caspase-independent apoptosis. Expression levels of full-length and cleaved caspase-3, -8 and -9 were detected by western blotting. (C) Cell lysates were immunoblotted to detect the expression levels of mitochondria-associated proteins. Relative expression levels of cleaved PARP, Bax and Bcl-xL were determined by normalizing the DMSO group levels to 1.0. Data are presented as the means \pm standard deviation from three independent experiments. " $\mathrm{P}<0.01$ vs. the DMSO group. Bax, B-cell lymphoma-2-associated X protein; Bcl-xL, B-cell lymphoma-extra large; DMSO, dimethyl sulfoxide; PARP, poly (ADP-ribose) polymerase; PI, propidium iodide. 
A

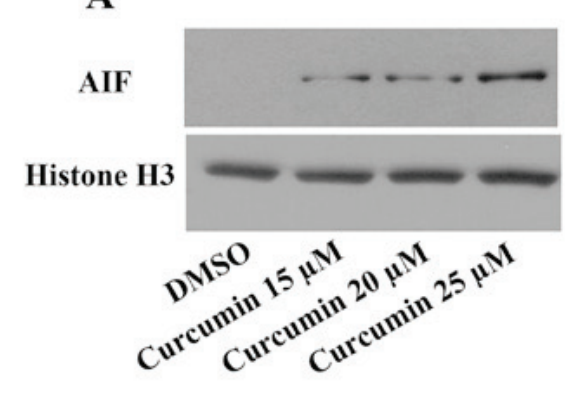

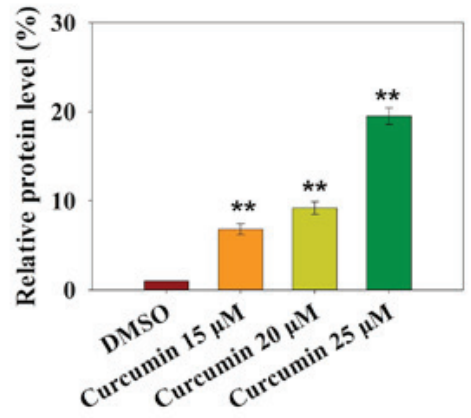

B
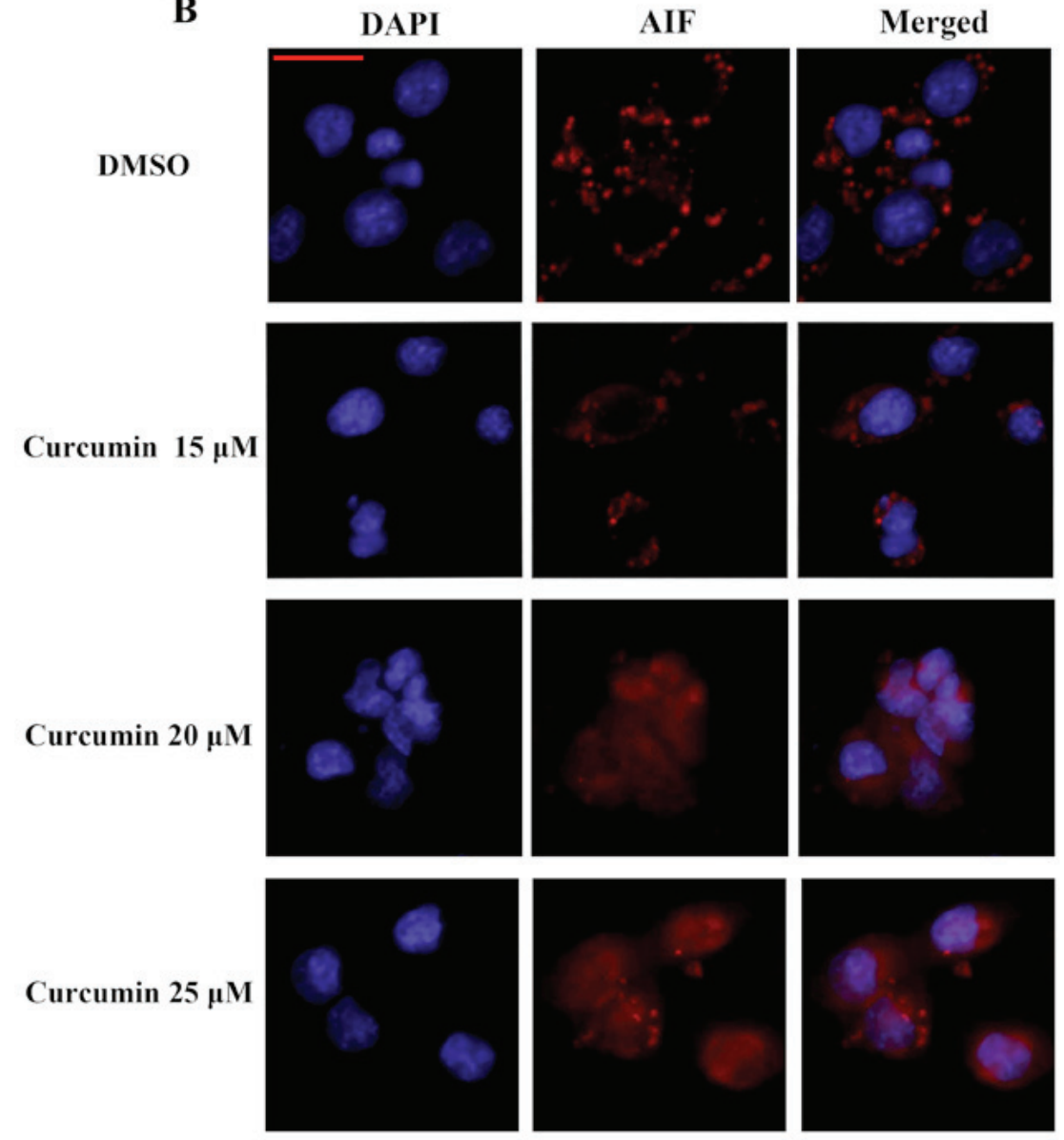

Figure 3. Curcumin induces caspase-independent apoptosis. (A) Nuclear protein was extracted from the cells following treatment with curcumin for 24 h, and the expression levels of AIF were detected in the nucleus by western blotting. Relative expression levels of AIF were determined by normalizing DMSO group levels to 1.0. Data are presented as the means \pm standard deviation of three independent experiments. ${ }^{* *} \mathrm{P}<0.01 \mathrm{vs}$. the DMSO group. (B) Translocation of AIF from the cytosol to the nucleus after RN5 cells were treated with curcumin for 24 h. Following incubation with an AIF primary antibody, cells were stained with an Alexa Fluor-555-conjugated goat anti-rabbit immunoglobulin G secondary antibody. Nuclei were stained with DAPI. Scale bar, $25 \mu$ m. AIF, apoptosis-inducing factor; DMSO, dimethyl sulfoxide.

results indicated that the caspase-independent AIF nuclear translocation-mediated apoptotic pathway may be involved in curcumin-induced cell death.

Curcumin induces apoptosis through suppression of the PI3K-Akt-mTOR signaling pathway. The PI3K-Akt-mTOR signaling pathway has a critical role in various cellular processes (21), including survival, proliferation, apoptosis and angiogenesis. Previous studies on cancer have revealed that curcumin inhibits the PI3K-Akt-mTOR signaling pathway $(22,23)$. Targeting the PI3K-Akt-mTOR signaling pathway, which is downstream of several activated receptor tyrosine kinases (RTKs) in mesothelioma, seems to be an emerging therapeutic strategy (24). As shown in Fig. 4A and $\mathrm{B}$, treatment with increasing doses of curcumin resulted in significant downregulation of PI3K, p-Akt, p-mTOR and p-p70S6K; however, no significant differences were detected with regards to the total expression levels of Akt, mTOR and p70S6K. These results suggested that the PI3K-Akt-mTOR signaling pathway may be involved in curcumin-induced apoptosis.

Curcumin inhibits tumor growth and angiogenesis in vivo. Tumor volume was significantly reduced following three 
A
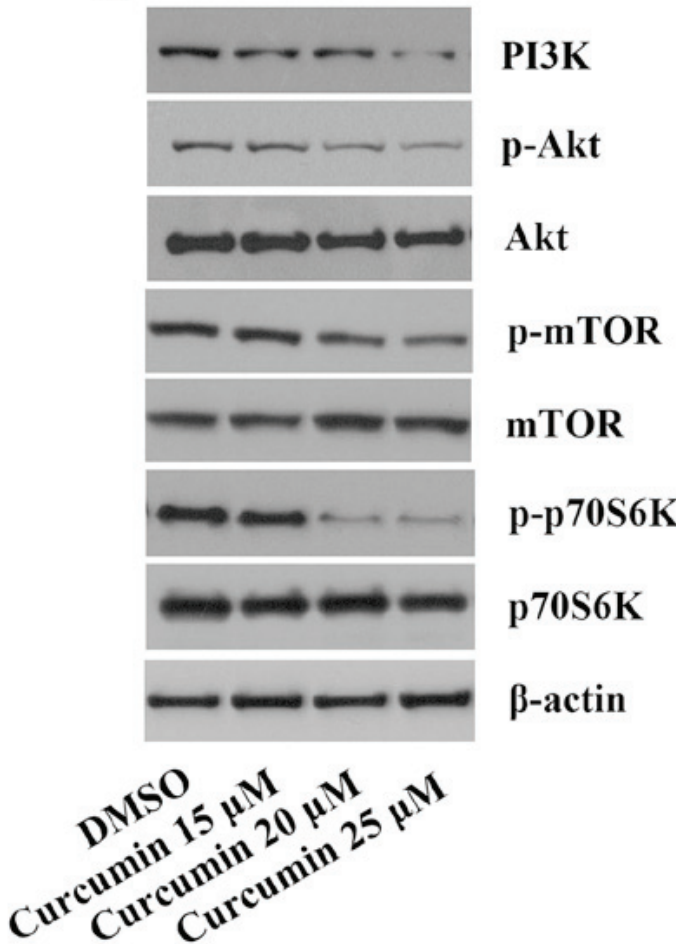

B
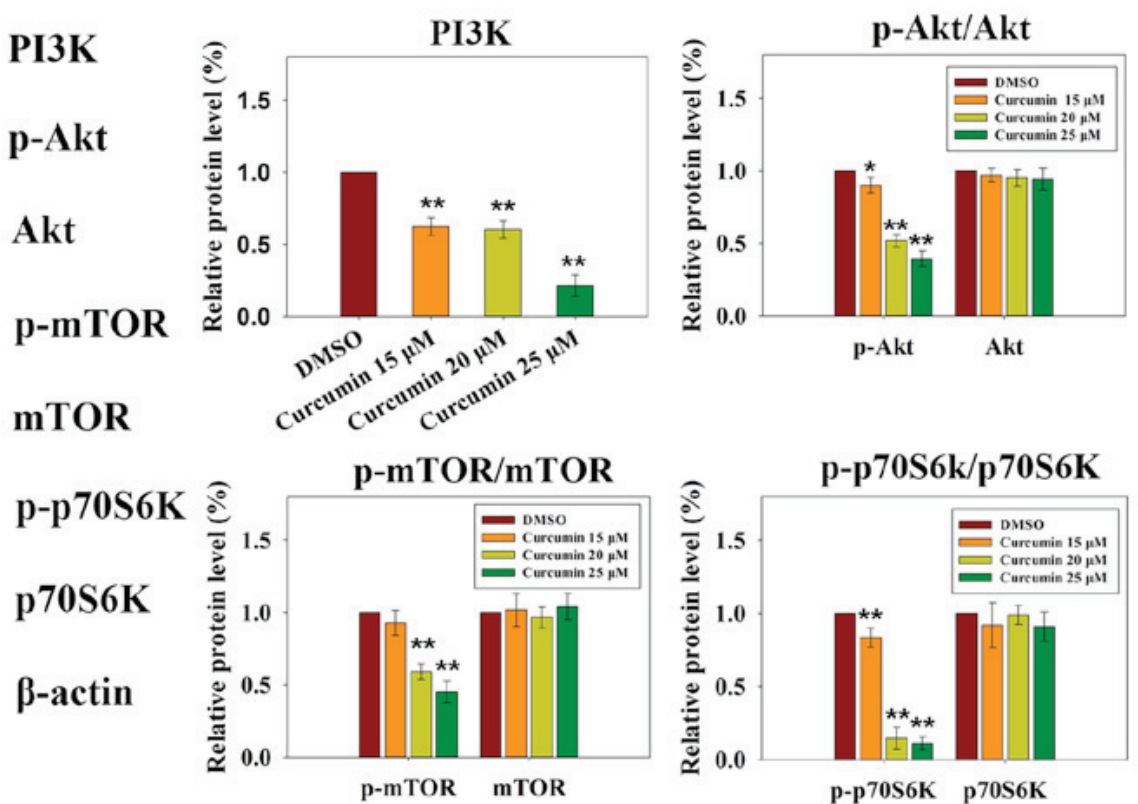

Figure 4. Effects of curcumin on the PI3K-Akt-mTOR signaling pathway. (A) Expression levels of PI3K-Akt-mTOR signaling pathway-associated proteins were detected in RN5 cells treated with various concentration of curcumin by western blotting. (B) Relative expression levels of PI3K, p-Akt/Akt, p-mTOR/ mTOR and p-p70S6K/p70S6K were determined by normalizing DMSO group levels to 1.0. Data are presented as the means \pm standard deviation of three independent experiments. ${ }^{*} \mathrm{P}<0.05$ and ${ }^{* *} \mathrm{P}<0.01$ vs. the DMSO group. Akt, AKT serine/threonine kinase; DMSO, dimethyl sulfoxide; mTOR, mammalian target of rapamycin; p, phosphorylated; P70S6k, p70 ribosomal protein S6 kinase; PI3K, phosphoinositide 3-kinase.

A

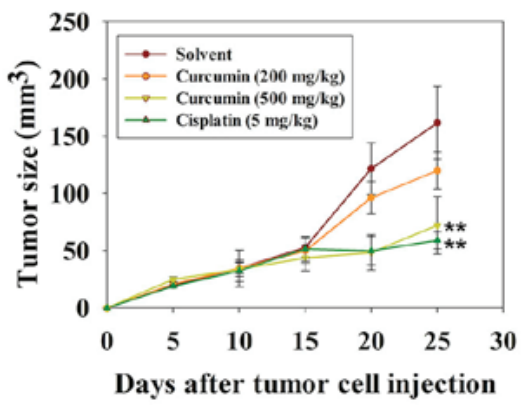

B

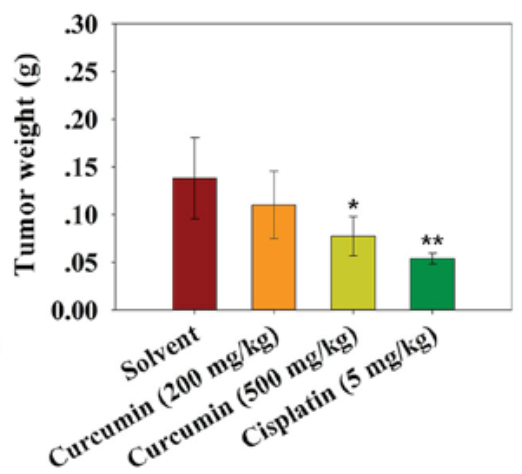

C

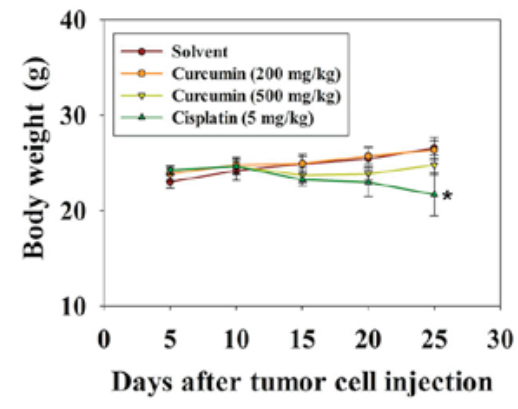

Figure 5. Antitumor effects of curcumin on mice injected with RN5 malignant mesothelioma cells in vivo. The mice received intraperitoneal injections with curcumin or cisplatin every 5 days; cisplatin was used as a positive control. The experiment was terminated and the mice were sacrificed on day 25 after the tumor challenge. There were 4-5 mice in each experimental group. (A) Antitumor effects of curcumin at a low (200 mg/kg) or high dose (500 mg/kg), or cisplatin $(5 \mathrm{mg} / \mathrm{kg})$. (B) Tumor weight of mice treated with curcumin or cisplatin on day 25 . (C) Body weight was measured throughout the experiment. ${ }^{*} \mathrm{P}<0.05$ and ${ }^{* *} \mathrm{P}<0.01$ vs. the solvent group.

injections of cisplatin and $500 \mathrm{mg} / \mathrm{kg}$ curcumin. The mean volumes of subcutaneous tumors in the cisplatin- and high dose curcumin-treated mice were decreased compared with in the vehicle control group (Fig. 5A and B). The experiment was terminated and the mice were sacrificed on day 25 following tumor cell injection. The mean tumor volumes in mice treated with cisplatin and a high dose of curcumin were 58 and $72 \mathrm{~mm}^{3}$, respectively, whereas the tumor volumes in mice treated with the solvent and a low dose of curcumin were 161 and $120 \mathrm{~mm}^{3}$ on day 25 . The body weight of the mice was also monitored, in order to evaluate the potential side effects of curcumin. As shown in Fig. 5C, there was no obvious body weight loss in mice treated with curcumin throughout the experiment, thus indicating that curcumin did not exert evident systemic toxicity at the doses used in this investigation. Body weight loss in mice treated with cisplatin reflected the toxicity of the drug towards normal tissue (Fig. 5C). These results suggested that curcumin may inhibit tumor growth in vivo with no obvious toxicity. 
A
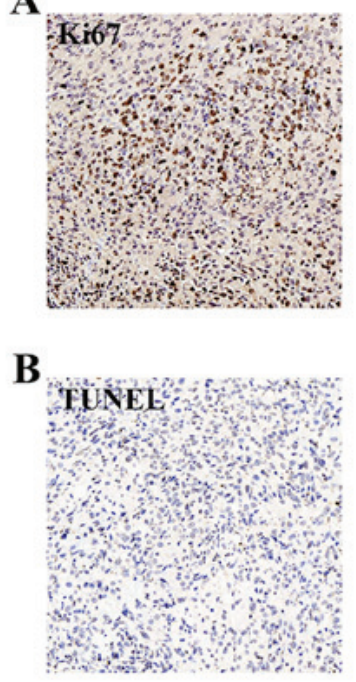

C

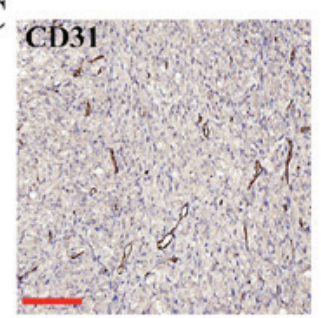

Solvent
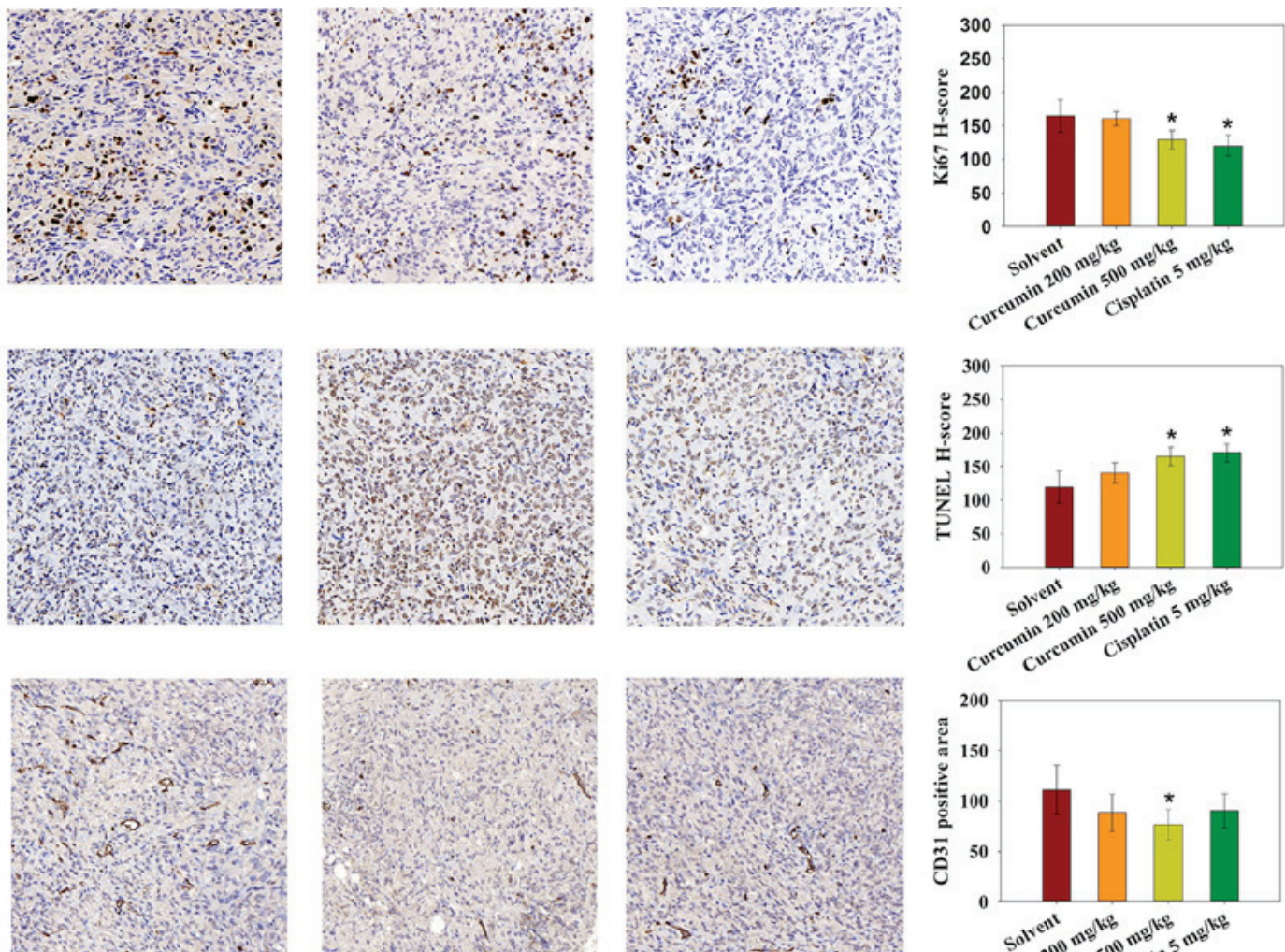

Curcumin $200 \mathrm{mg} / \mathrm{kg}$

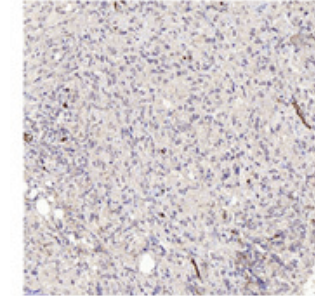

Curcumin $500 \mathrm{mg} / \mathrm{kg}$
Cisplatin $5 \mathrm{mg} / \mathrm{kg}$
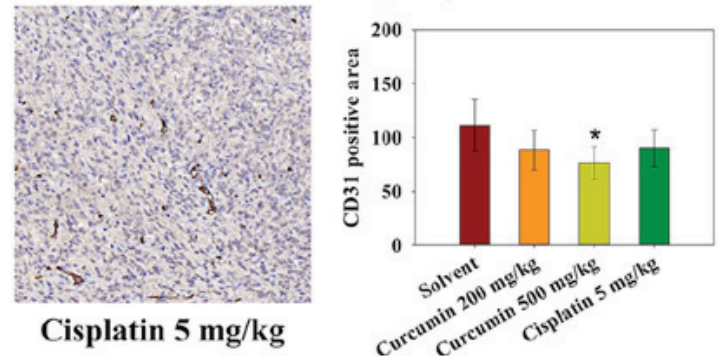

Figure 6. Effects of curcumin on angiogenesis, cell proliferation and apoptosis in tumor-bearing mice, as determined by Ki67, TUNEL and CD31 staining. Representative histological micrographs of (A) Ki67, (B) TUNEL and (C) CD31 staining. (A and B) Ki67 and TUNEL staining was semi-quantitatively evaluated by $\mathrm{H}$-score. (C) CD31 was semi-quantified by determining the positive area percentage. Data are expressed as the means \pm standard deviation. There were 4-5 mice in each experimental group. Scale bar, $100 \mu \mathrm{m}$. ${ }^{*} \mathrm{P}<0.05$ vs. the solvent group. CD31, cluster of differentiation 31.

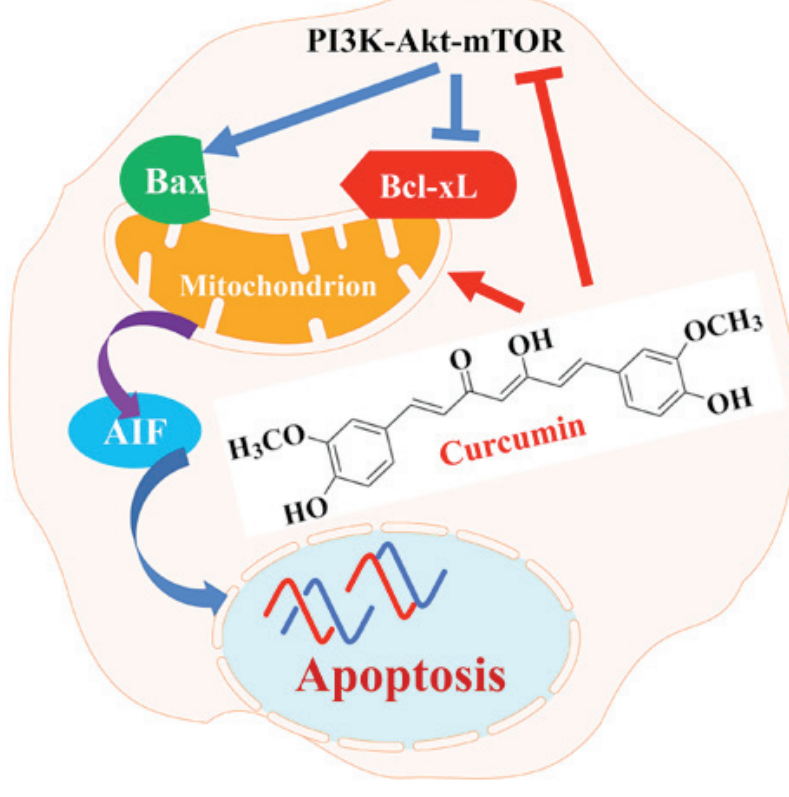

Figure 7. Schematic diagram indicating how curcumin exerts anticancer effects on RN5 murine mesothelioma cells. Curcumin suppressed PI3K-Akt-mTOR signaling pathway by downregulating PI3K, p-Akt, p-mTOR and p-p70S6K and induced apoptosis through mitochondrial, caspase-independent and AIF-dependent pathways. AIF, apoptosis-inducing factor; Akt, AKT serine/threonine kinase; Bax, B-cell lymphoma-2-associated X protein; Bcl-xL, B-cell lymphoma-extra large; mTOR, mammalian target of rapamycin; $p$, phosphorylated; P70S6k, p70 ribosomal protein S6 kinase; PI3K, phosphoinositide 3-kinase.
As tumor cell proliferation and inhibition of apoptosis are attributable to tumor growth, Ki-67 immunohistochemistry and TUNEL analysis were performed on tumor sections. As shown in Fig. 6A and B, treatment with cisplatin or a high dose of curcumin affected the number of proliferating Ki-67-positive cells. In addition, using TUNEL cell death detection, it was revealed that tumors from the cisplatin and high-dose curcumin groups contained an increased number of TUNEL-positive apoptotic cells. CD31 immunostaining was also conducted to evaluate tumor angiogenesis following curcumin treatment in mice. The positive area of CD31 was significantly lower in the high dose curcumin-treated group (Fig. 6C). These results indicated that curcumin may inhibit tumor growth through inducing apoptosis, and inhibiting cell proliferation and angiogenesis.

\section{Discussion}

The present study demonstrated that curcumin induced apoptotic cell death of RN5 murine cells via the AIF-dependent pathway and suppression of the PI3K-Akt-mTOR signaling pathway (Fig. 7). Further analysis indicated that curcumin may suppress tumor growth and angiogenesis without systemic toxicity in vivo. These results indicated that curcumin may be a promising anti-mesothelioma agent.

Curcumin treatment for $24 \mathrm{~h}$ markedly upregulated Bax expression and PARP cleavage, and downregulated Bcl-xL. 
Bcl-2 family members, which mediate cleavage of PARP, are major regulators of the mitochondrial apoptotic pathway. The present findings demonstrated that curcumin-induced RN5 cell death may be caused by the mitochondrial apoptotic pathway. It has previously been reported that curcumin induces apoptosis through the death receptor and mitochondrial pathways (25). The caspase cascade serves a vital role in apoptosis. In numerous cell types, including in mesothelioma cells, curcumin-stimulated apoptosis has been revealed to be induced via the caspase-mediated pathway $(12,22,25)$. Caspase- 3 is downstream of the activator caspases and acts to cleave various targets. In the present study, cleaved caspase-3 expression was significantly upregulated by cisplatin treatment, whereas cleaved caspase-3, -8 and -9 expression was not detected following curcumin treatment. The caspase- 3 and -9 antibodies used in this study can detect both full length and cleaved caspase fragments. In addition, antibodies against caspase- 8 and cleaved caspase- 8 were used to detect endogenous levels of caspase- 8 ( 45 or $57 \mathrm{kDa}$ ), and active caspase- 8 [p18 and cleavage products containing the pro-domain with the p18 subunit (p43)]. Incubation with the cleaved caspase- 8 antibody did not detect any signal following RN5 cell treatment, even in cells treated with cisplatin. AIF is a mitochondrial intermembrane space-localized flavoprotein that is released by mitochondria and translocated to the nucleus in response to death stimuli. AIF serves key roles in caspase-independent apoptosis. To further confirm whether curcumin-induced apoptosis was mediated by AIF, AIF expression was detected in the nucleus by western blotting, and AIF translocation from the mitochondria to the nucleus was analyzed by immunofluorescence. The results indicated that AIF was translocated from the cytoplasm to the nucleus, and its expression was increased with increasing doses of curcumin. Several studies have reported that X-rays and other natural agents induce AIF-dependent apoptosis (26,27). The present study demonstrated that curcumin induced apoptosis through activation of the caspase-independent pathway in RN5 cells.

The PI3K-Akt-mTOR signaling pathway is activated in cancer and is known to have a key role in a wide range of cellular processes, including apoptosis inhibition, cell proliferation and angiogenesis. Activation of the PI3K-AKT pathway in tumor cells can also increase vascular endothelial growth factor (VEGF) secretion, via hypoxia-inducible factor 1-dependent and -independent mechanisms. The PI3K-Akt-mTOR signaling pathway is downstream of several hyperactive RTKs in mesothelioma, thus indicating that this signaling pathway may be a promising target for the treatment of this disease. Dual PI3K-mTOR inhibitors inhibit Akt activation through the mTOR complex 1/P70S6K negative feedback loop (28). At present, $>50$ drugs have been developed based on inhibiting this signaling pathway (29).

On the basis of the curcumin-induced effects detected in RN5 cells, the present study aimed to determine the effects of curcumin on tumor-bearing mice. Treatment with a high dose of curcumin, $500 \mathrm{mg} / \mathrm{kg}$, inhibited tumor growth with low toxicity. Previous studies have used similar doses of curcumin (30,31). Furthermore, even low doses of cisplatin $(5 \mathrm{mg} / \mathrm{kg})$ exerted evident side effects. Resistance to cytotoxic drug-induced apoptosis is a main limitation in current mesothelioma chemotherapy. Some targeted chemotherapy agents have still not shown promise in clinical trials. Epidermal growth factor receptor (EGFR) overexpression has been detected in $>50 \%$ of mesothelioma specimens (32); however, erlotinib and gefitinib, as first-generation tyrosinekinase inhibitors (TKIs) that specifically target EGFR, have failed to exhibit significant activity in clinical trials. The proposed mechanism underlying resistance to these TKIs may be associated with activation of the PI3K-Akt downstream pathway. Curcumin inhibits drug-resistant cancer cell proliferation due to its regulation of numerous targets involved in drug resistance, including its ability to downregulate the multidrug-resistance gene $(33,34)$, and inhibit the nuclear factor (NF)- $\kappa \mathrm{B}$ signaling pathway (35) or the NF- $\kappa \mathrm{B}$ transcription factor (36).

Angiogenesis is an independent prognostic factor in MPM (37). The VEGF signaling pathway is associated with MPM growth; 31.5 and $66.7 \%$ cases of MPM express VEGF and VEGF-C, respectively (38). These previous findings indicated that VEGF inhibitors may be promising therapeutic agents. The addition of nintedanib to the pemetrexed plus cisplatin strategy in the treatment of MPM is associated with an improvement in progression-free survival (39). In addition, another VEGF inhibitor, cediranib, is in phase I/II clinical trials (40). Despite curcumin inhibiting angiogenesis through the VEGF-VEGF receptor 2 signaling pathway in some types of cancer (41), the mechanism underlying curcumin-induced inhibition of angiogenesis in MPM remains to be elucidated.

In conclusion, the present results demonstrated that curcumin induced apoptosis via the mitochondrial pathway and was involved in caspase-independent apoptotic signaling. In addition, curcumin inhibited the PI3K-Akt-mTOR signaling pathway, and suppressed tumor cell viability and angiogenesis, without evident toxicity in vivo. The present study indicated that a connection exists between the PI3K pathway and angiogenesis in mesothelioma. These findings may provide a promising application for curcumin, and indicated that the synergistic therapy of curcumin plus platinum-based cytotoxic agents may be promising in MPM treatment.

\section{Acknowledgements}

The authors of the present study would like to thank Mr. Samuel (Jia Wei) Liu (Honours Life Sciences, McMaster University, Hamilton, ON, Canada), and Ms. Alice Chen (Medical Sciences, Western University, London, ON, Canada) for editing this manuscript.

\section{Funding}

The present study was supported by grants from the Natural Science Foundation of Shandong Province (grant no. ZR2015HM054), the Key Research and Development Program of Shandong Province (grant nos. 2015GSF118144 and 2016ZDJS07A15), the Shandong Province Science and Technology Department Non-profit Program (grant no. 2014kjhm0107) and the Youth Talent Innovation Foundation of the Second Hospital of Shandong University (grant no. 2018YT17). 


\section{Availability of data and materials}

All data generated or analyzed during this study are included in this published article.

\section{Authors' contributions}

$\mathrm{XZ}, \mathrm{XD}, \mathrm{CZ}$ and $\mathrm{YH}$ conceived and designed this study. $\mathrm{CZ}$, $\mathrm{YH}, \mathrm{NJ}, \mathrm{JL}$ and $\mathrm{WZ}$ performed the experiments. XZ, LW, BC and DT analyzed and interpreted the data. CZ, XD, LW and MdP wrote the paper. MdP participated in general supervision of this study, discussion and interpretation of the results, and provided the MPM cell line. All authors have read and approved the manuscript.

\section{Ethics approval and consent to participate}

The present study was carried out in accordance with the National Institutes of Health guidelines outlined in the Guide for the Care and Use of Laboratory Animals. The animal study was approved by the Committee on the Ethics on Animal Experimentation of the Second Hospital of Shandong University [grant no. KYLL-2017(LW) 011, approved on February 3, 2017].

\section{Patient consent for publication}

Not applicable.

\section{Competing interests}

The authors declare that they have no competing interests.

\section{References}

1. Robinson BWS, Musk AW and Lake RA: Malignant mesothelioma. Lancet 366: 397-408, 2005.

2. Scherpereel A, Astoul P, Baas P, Berghmans T, Clayson H, de Vuyst P, Dienemann H, Galateau-Salle F, Hennequin C, Hillerdal G, et al; European Respiratory Society/European Society of Thoracic Surgeons Task Force: Guidelines of the European Respiratory Society and the European Society of Thoracic Surgeons for the management of malignant pleural mesothelioma. Eur Respir J 35: 479-495, 2010.

3. Perrot M, Wu L, Wu M and Cho BCJ: Radiotherapy for the treatment of malignant pleural mesothelioma. Lancet Oncol 18 e532-e542, 2017.

4. Milano MT and Zhang H: Malignant pleural mesothelioma: A population-based study of survival. J Thorac Oncol 5: 1841-1848, 2010.

5. Kaku Y, Nagaya H, Tsuchiya A, Kanno T, Gotoh A, Tanaka A, Shimizu T, Nakao S, Tabata C, Nakano T, et al: Newly synthesized anticancer drug HUHS1015 is effective on malignant pleural mesothelioma. Cancer Sci 105: 883-889, 2014.

6. Altomare DA, You H, Xiao GH, Ramos-Nino ME, Skele KL, De Rienzo A, Jhanwar SC, Mossman BT, Kane AB and Testa JR: Human and mouse mesotheliomas exhibit elevated AKT/PKB activity, which can be targeted pharmacologically to inhibit tumor cell growth. Oncogene 24: 6080-6089, 2005.

7. Anand P, Sundaram C, Jhurani S, Kunnumakkara AB and Aggarwal BB: Curcumin and cancer: An 'old-age' disease with an 'age-old' solution. Cancer Lett 267: 133-164, 2008.

8. Kunnumakkara AB, Anand P and Aggarwal BB: Curcumin inhibits proliferation, invasion, angiogenesis and metastasis of different cancers through interaction with multiple cell signaling proteins. Cancer Lett 269: 199-225, 2008

9. Miller JM, Thompson JK, MacPherson MB, Beuschel SL, Westbom CM, Sayan M and Shukla A: Curcumin: A double hit on malignant mesothelioma. Cancer Prev Res (Phila) 7: 330-340, 2014.
10. Yamauchi Y, Izumi Y, Asakura K, Hayashi Y and Nomori H: Curcumin induces autophagy in ACC-MESO-1 cells. Phytother Res 26: 1779-1783, 2012.

11. Masuelli L, Benvenuto M, Di Stefano E, Mattera R, Fantini M, De Feudis G, De Smaele E, Tresoldi I, Giganti MG, Modesti A, et al: Curcumin blocks autophagy and activates apoptosis of malignant mesothelioma cell lines and increases the survival of mice intraperitoneally transplanted with a malignant mesothelioma cell line. Oncotarget 8: 34405-34422, 2017.

12. Wang Y, Rishi AK, Wu W, Polin L, Sharma S, Levi E, Albelda S, Pass HI and Wali A: Curcumin suppresses growth of mesothelioma cells in vitro and in vivo, in part, by stimulating apoptosis. Mol Cell Biochem 357: 83-94, 2011.

13. Blum W, Pecze L, Felley-Bosco E, Worthmüller-Rodriguez J, Wu L, Vrugt B, de Perrot M and Schwaller B: Establishment of immortalized murine mesothelial cells and a novel mesothelioma cell line. In Vitro Cell Dev Biol Anim 51: 714-721, 2015.

14. Zhang C, Zhai S, Li X, Zhang Q, Wu L, Liu Y, Jiang C, Zhou H, Li F, Zhang S, et al: Synergistic action by multi-targeting compounds produces a potent compound combination for human NSCLC both in vitro and in vivo. Cell Death Dis 5: e1138, 2014.

15. Zhang C, Zhai S, Wu L, Bai Y, Jia J, Zhang Y, Zhang B and Yan B: Induction of size-dependent breakdown of blood-milk barrier in lactating mice by $\mathrm{TiO}_{2}$ nanoparticles. PLoS One 10: e0122591, 2015.

16. Detre S, Saclani Jotti G and Dowsett M: A "quickscore" method for immunohistochemical semiquantitation: Validation for oestrogen receptor in breast carcinomas. J Clin Pathol 48: 876-878, 1995.

17. Jordan RC, Lingen MW, Perez-Ordonez B, He X, Pickard R, Koluder M, Jiang B, Wakely P, Xiao W and Gillison ML: Validation of methods for oropharyngeal cancer HPV status determination in US cooperative group trials. Am J Surg Pathol 36: $945-954,2012$.

18. Lee SJ, Krauthauser C, Maduskuie V, Fawcett PT, Olson JM and Rajasekaran SA: Curcumin-induced HDAC inhibition and attenuation of medulloblastoma growth in vitro and in vivo. BMC Cancer 11: 144, 2011.

19. Subramaniam D, May R, Sureban SM, Lee KB, George R, Kuppusamy P, Ramanujam RP, Hideg K, Dieckgraefe BK, Houchen CW, et al: Diphenyl difluoroketone: A curcumin derivative with potent in vivo anticancer activity. Cancer Res 68: 1962-1969, 2008.

20. Budihardjo I, Oliver H,Lutter M, Luo X and Wang X: Biochemical pathways of caspase activation during apoptosis. Annu Rev Cell Dev Biol 15: 269-290, 1999.

21. Fruman DA and Rommel C: PI3K and cancer: Lessons, challenges and opportunities. Nat Rev Drug Discov 13: 140-156, 2014.

22. Fu H, Wang C, Yang D, Wei Z, Xu J, Hu Z, Zhang Y, Wang W, Yan R and Cai Q: Curcumin regulates proliferation, autophagy, and apoptosis in gastric cancer cells by affecting PI3K and P53 signaling. J Cell Physiol 233: 4634-4642, 2018.

23. Banik U, Parasuraman S, Adhikary AK and Othman NH: Curcumin: The spicy modulator of breast carcinogenesis. J Exp Clin Cancer Res 36: 98, 2017.

24. Echeverry N, Ziltener G, Barbone D, Weder W, Stahel RA, Broaddus VC and Felley-Bosco E: Inhibition of autophagy sensitizes malignant pleural mesothelioma cells to dual PI3K/ mTOR inhibitors. Cell Death Dis 6: e1757, 2015.

25. Hu A, Huang JJ, Li RL, Lu ZY, Duan JL, Xu WH, Chen XP and Fan JP: Curcumin as therapeutics for the treatment of head and neck squamous cell carcinoma by activating SIRT1. Sci Rep 5: $13429,2015$.

26. Yang S, Huang J, Liu P, Li J and Zhao S: Apoptosis-inducing factor (AIF) nuclear translocation mediated caspase-independent mechanism involves in X-ray-induced MCF-7 cell death. Int J Radiat Biol 93: 270-278, 2017.

27. Cho H-D, Lee J-H, Moon K-D, Park K-H, Lee M-K and Seo K-I: Auriculasin-induced ROS causes prostate cancer cell death via induction of apoptosis. Food Chem Toxicol 111: 660-669, 2018.

28. Rodrik-Outmezguine VS, Chandarlapaty S, Pagano NC, Poulikakos PI, Scaltriti M, Moskatel E, Baselga J, Guichard S and Rosen N: mTOR kinase inhibition causes feedback-dependent biphasic regulation of AKT signaling. Cancer Discov 1: 248-259, 2011.

29. Pons-Tostivint E, Thibault B and Guillermet-Guibert J: Targeting PI3K signaling in combination cancer therapy. Trends Cancer 3: 454-469, 2017. 
30. Fetoni AR, Paciello F, Mezzogori D, Rolesi R, Eramo SL, Paludetti G and Troiani D: Molecular targets for anticancer redox chemotherapy and cisplatin-induced ototoxicity: The role of curcumin on pSTAT3 and Nrf-2 signalling. Br J Cancer 113: 1434-1444, 2015.

31. Dienstmann R, Rodon J, Serra V and Tabernero J: Picking the point of inhibition: A comparative review of PI3K/AKT/mTOR pathway inhibitors. Mol Cancer Ther 13: 1021-1031, 2014.

32. Bronte G, Incorvaia L, Rizzo S, Passiglia F, Galvano A, Rizzo F, Rolfo C, Fanale D, Listì A, Natoli C, et al: The resistance related to targeted therapy in malignant pleural mesothelioma: Why has not the target been hit yet? Crit Rev Oncol Hematol 107: 20-32, 2016.

33. Choi BH, Kim CG, Lim Y, Shin SY and Lee YH: Curcumin downregulates the multidrug-resistance mdrlb gene by inhibiting the PI3K/Akt/NF kappa B pathway. Cancer Lett 259: 111-118, 2008.

34. Chearwae W, Anuchapreeda S, Nandigama K, Ambudkar SV and Limtrakul P: Biochemical mechanism of modulation of human P-glycoprotein (ABCB1) by curcumin I, II, and III purified from Turmeric powder. Biochem Pharmacol 68: 2043-2052, 2004.

35. Bava SV, Puliyappadamba VT, Deepti A, Nair A, Karunagaran D and Anto RJ: Sensitization of taxol-induced apoptosis by curcumin involves down-regulation of nuclear factor-kappaB and the serine/threonine kinase Akt and is independent of tubulin polymerization. J Biol Chem 280: 6301-6308, 2005.

36. Dhandapani KM, Mahesh VB and Brann DW: Curcumin suppresses growth and chemoresistance of human glioblastoma cells via AP-1 and NFkappaB transcription factors. J Neurochem 102: 522-538, 2007.
37. Edwards JG, Cox G, Andi A, Jones JL, Walker RA, Waller DA and O'Byrne KJ: Angiogenesis is an independent prognostic factor in malignant mesothelioma. Br J Cancer 85: 863-868, 2001.

38. Ohta Y, Shridhar V, Bright RK, Kalemkerian GP, Du W, Carbone M, Watanabe Y and Pass HI: VEGF and VEGF type C play an important role in angiogenesis and lymphangiogenesis in human malignant mesothelioma tumours. Br J Cancer 81: 54-61, 1999.

39. Grosso F, Steele N, Novello S, , Nowak AK, Popat S, Greillier L, John T, Leighl NB, Reck M, Taylor P, et al: Nintedanib plus pemetrexed/cisplatin in patients with malignant pleural mesothelioma: Phase II results from the randomized, placebocontrolled LUME-meso trial. J Clin Oncol 35: 3591-3600, 2017.

40. Yap TA, Aerts JG, Popat S and Fennell DA: Novel insights into mesothelioma biology and implications for therapy. Nat Rev Cancer 17: 475-488, 2017

41. Fu Z, Chen X, Guan S, Yan Y, Lin H and Hua ZC: Curcumin inhibits angiogenesis and improves defective hematopoiesis induced by tumor-derived VEGF in tumor model through modulating VEGF-VEGFR2 signaling pathway. Oncotarget 6: 19469-19482, 2015.

This work is licensed under a Creative Commons Attribution-NonCommercial-NoDerivatives 4.0 International (CC BY-NC-ND 4.0) License. 